\title{
The Repair of Organizational Trust:An Investigation from Literature Review Study
}

\begin{abstract}
Alfred P. Nehlar ${ }^{1}$
Abstract

The article discusses repairing organizational trust and provides insights into the dynamic rebuilding process of trust, as the current experience of organizational employees due to COVID-19 spills. The article focuses on repairing trust, as shown by Kim et al. (2009) and Hope et al. (2012), about institution or organization for existing literature on trust repair by utilizinga quantitative approach to analyze secondary data. The article examines the subject of trust repair by highlighting flaws of trust, the mechanism of trust repair as they vary at the level of organization. The analyst provided analytical structures, theories on the repair of organizational trust, and explored research practices. The article finds and addresses theory and methods that govern literature of trust repair. The author argues that this research should be augmented with progressive viewpoints for deeper and extending comprehension. The article finally concludes by setting forth exciting prospects for potential study.
\end{abstract}

Keywords: Institutional Trust; Organizational Trust; Trust Repair; Third Parties; Stakeholders

\section{Introduction}

The repair of organizational trust is an essential component of every organization with a problem of crisis. Nevertheless, as demonstrated by notable corporate governance economic turmoil, it is often challenging to repair trust once it is broken (Kramer et al., 2010).The knowledge of how to recover the organizational trust has been a significant subject for both organizational scholars and practitioners over the last decade (Kramer et al., 2010; Bachmann et al., 2015).

The epidemic of COVID-19 (Coronavirus) is a recent illustration that illustrates the realistic nature of this research. With the outbreak of COVID-19, global business and economic uncertainty have increased. Research shows that the epidemic of COVID-19 would drive global gross domestic product (GDP) for the full year from 2,5\% projected to zero percent in January 2020 (Barr, 2020). Organizations are dealing with the effect of an epidemic on their ability to fulfill business targets and client expectations in this crisis management environment.

COVID-19 spillovers would undoubtedly contribute to further workforce control, travel limits, consumer spending reduction, postponed expenditures, broken supply ties, and financial sector instability that will trigger workers to lose and break the organizational trust between employers and employees that has existed in our resented past.The workers are the organization's biggest strength. In periods of crisis, organizations are liable for behaving in the best interests of their employees, their clients, and other stakeholders. This allows companies to adapt to fast changes and to restore trust. The leak hit the stakeholders of companies, eroded trust, hit the credibility of the business, and subject the organization to hundreds of millions of retrieval costs, sanctions, and possible liabilities for the workforce.In this article, the author discusses new research on restoring organizational trust and provides insights into the dynamic repairprocess of trust.

\section{The methodology of the study}

This article utilizes a quantitative approach to analyze secondary data from organizational trust reports, research articles, and internet accounts.By (Burnham, Karin, Wyn, \& Zig, 2008), qualitative analyses produce a wide range of knowledge from different sources and provide an in-depth study of a phenomenon. It offers a more thorough and accurate description under review. The research used no primary data points but carefully analyzed the literature and secondary evidence on the repair of organizational trust. This article focuses on the challenges to repair trust once it is broken. In this context, the central research question motivating this study arises:

\section{What does repairing trust in an institution or organization mean?}

Fundamentally, repairingthis macro-level trustnecessitatesrebuilding the constructive attitudes of trusting agencies or organizations affected by a breach of trust so trusts can become susceptible again (Lewicki et al., 1996; Kramer et al., 2010).

\footnotetext{
${ }^{1}$ Mr. Alfred P. Nehlar, is a candidate for a Master in Public Administration at the School of Public Affairs, University of Science and Technology of China, 96 Jinzhai Road, Hefei, 230026, Anhui, China. E-mail: anehlar@mail.ustc.edu.cn
} 
Dirks et al. (2009) indicate that relationship repair requires "activities by either or both parties which restore the partnership substantively to a prosperous state underlining that confidence repairs are necessary and affected not just by the contravener but also by the confidence individual" (Dirks et al., 2009, p. 69). However, in this study, third parties contribute immensely to rebuilding organizational trust.

\section{The subject of trust repair}

The plurality of meanings of trust repair refers to what Dirks and associates "define as a mechanism in which a trustee attempts to restore trust in a case where a transgression is deemed untrustworthy" (2011, p. 88). This implies that "relationship repair takes place when a transgression causes the positive state which constitutes a relationship to vanish and negative disposition to emerge when one or both parties view it, and the actions of one or both parties which offer the relationship back to a positive state significantly" (Dirks et al., 2009, p.69). The fundamental goal of trust repair is to restore cooperation and reestablish constructive anticipations of the trustee by the other party andto render himself insecure (Kramer et al., 2010; Desmet et al., 2011).

\subsection{Trust repair at the organizational level}

The research focuses on rebuilding trust in the counter-argument of the organization.The sociological literature on trust has historically been incorporated into the studies of organizational and institutional trust (Fox, 1974; Luhmann, 1979; Barber, 1983).Nevertheless, much research works meaningfully researching trust repair had been carried out on an interpersonal basis. Organizational and institutional trust repairs have similarities to the reparation of interpersonal trust and numerous significant variations that restrict study results to a range of components (Gillespie et al., 2009; Fulmer et al., 2012).

In contrast to a social trust in which an individual or leader is the focus, trust in the institutional and organizational context is often more complicated and demanding.It is partially because a variety of organizational stakeholders and infrastructure at many dimensions will manipulate and persuade future trustees' decisions (Gillespie et al., 2009). If one trusts in an organization, one trusts in the human relationships or trusts one more in the interpersonal set of mechanisms, processes, and practices, which generally regulate the conduct of organizational members (Luhmann, 1979; Möllering, 2001).

The prevailing cultural ideals and beliefs to which representatives of the organization and its officials appear to conform are therefore granted higher priority, and integrity of the company and nature of its products and services are under doubt. By Bachmann et al. (2011, p. 284), institutional trust is "constitutively incorporated in a relationshipbased institutional environment." The author comes from the viewpoint that stakeholder trust in an organization is reassured and that both of these factors should be integrated (Barber, 1983; Gillespie et al., 2009).

Organizational trust repairs further represent the variety of stakeholders served by trusts in organizations and entities, including staff, vendors, consumers, creditors, policymakers, administrations, and the community. Such stakeholders have varied concerns, insecurity, influence, and perceptions about organizations, structures, and organizations (Pfarrer et al., 2008). Because they vary in acquaintance, availability, and thus an understanding of organizational behavior and institutional arrangements, they can develop trust in various ways. In reality, it is much more complex to repair trust at the macro level shareholders may vary in their understandings of the violation than at the interpersonal level and thus provide credible ways to restore relations (Lamin et al., 2012; Bachmann et al., 2015).

\subsection{Trust failures at the organizational level}

In repairing trust, it is essential to understand the failures of trust. The failures of trust can be attributed to many characteristics and many forms. However,there must be standardized, distinguishing attributes to ensure that a trust failure is accredited to the level of organization. The failure of the organizational trust has been one of the significant events or collective accident, in the behavior or inaction of organizational agents. They endanger the organization's credibility and could affect the well-being of one or more stakeholders of the company (Gillespie et al., 2009).

If violating trust is to take place at the organizational or institutional level, it must call into question the legitimacy of the organization or institution, its fundamental responsibilities, or the shared values and norms it endorses. At least the trustee shall assign any blame for infringement to the organization or institution and shall be held to be at least partially liable for acts or the inaction of remiss actors permitted or otherwise facilitated by the institutional structures in question. The situation would be followed by pessimistic assumptions that an agency or entity must meet fair levels of competence, generosity, and honesty in its conduct with participants. 
Organizational trust failures take several types, including accounting fraud, administrative manipulation, and negligence, tragic, avoidable accidents, abuse of the insecure, large-scale mandatory employment cuts, recession, and disastrous corporate finance breakups. For trust to collapse at a larger systemic stage, trustors need to recognize that a breakdown exists in many structural institutions, even businesses collapsing in the global financial crisis; substance misuse is present in many organizations, and the loss happens in the administrative structures themselves.

At one extreme, losing trust may result from a single disastrous event like the one suffered by organizational employee and employer due to COVID-19 spills. On the other end, a failure will arise based on the buildup of trust violations that wear away trust over time. Here, an inflection point is when the trustor loses trust in the credibility of the organization (Kramer, 2010; Bachmann et al., 2015).

\section{Conceptualization and theoretical mechanisms of trust repair}

The author first discussed the underlying theoretical frameworks that reinforce the repair of organizational trust. Dirks and colleagues describe three theoretical mechanisms to explain trust attribution, structural, and structural repair of trust(Dirks et al., 2009). Bachmann et al. (2015) recently recommended six compatible repair strategies consolidative models that integrate the three proposed frameworks by Dirks and colleagues. The author has developed this current approach to inform and theorize trust repair approaches, with findings from chosen experiential research on the repair of trust in institutions and organizations.

This method focuses on reasoning and social mechanisms. It is focused on the principle that a conventional interpretation or agreed interpretation of a trustviolation is needed for a successful confidence reparation, including a clarification of what went wrong and why, as illustrated by (Bachmann et al., 2015). The entire system contains but more systematic than attribution methodologies, directed at deciding if perceivers have perpetrated a violation or if their true nature more expressed or if they are experiencing forgiveness(Dirks et al., 2009). The approaches require study and inquiry to comment officially on the circumstances and why and clarify, refute, apologize for concrete interventions, and suggestions of penances intended at changing the acknowledgments (Elsbach, 1994; Kim et al., 2006).

The two-stage trust repair model, Kim et al. (2009), also highlights aspects of organizational trust reparation with a focus on interpersonal relations. The model presented by them presumes that questions will settle disputes between trustees and trusted regarding trustworthiness after a breach: "Was the trustee liable or guilty for the offense? (2) Should the trustee be attributed to the condition or the individual when he is guilty of transgression? (3) When the violation is at least partly due to the individual, the defect may be corrected, or is it a permanent trait of the trustee?. Analyzing the mechanisms by which people render attributions to others, these students clarify why such repair attempts can succeed sometimes, but not in other circumstances. The article also argued that the trustee and transgressor contribute activelyto the repair of trust.

Tomlinson et al. (2009) also fairly established a clear trust repair attribution theory. The philosophy is based on a causal assumption that trusts attribute the reason of adverse results to an absence of kindness, competence, and integrity of the trustee and the causal assumption that the undesirable result is due to external influences versus internal, controllable versus uncontrollably and temporarily unstable versus permanent, unchanging characteristics. Tomlinson et al. (2009) propose to remedy damaged perceptions of trustworthiness through attribution processes, such as denial, excussion, apology, and justification.

That, for example, helps the senior management to rectify their impressions about a lack of skill or capacity for senior managers by demonstrating that the adverse result was attributed to an external factor such as the 2008 global financial collapse or the debt crisis of 2012.An analysis of notable trust failures shows that companies utilize this form of accounting to manipulate stakeholder characteristics and context (Dietz et al., 2012; Elsbach, 1994).

\subsection{The analytical approach}

The analytical strategy reflects the feelings of social patterns in the repaircycle. The strategy is focused on research, which says that social norms and symbolic behavior must overcome detrimental feelings triggered by a breakdown of the partnership and to restore social order and standards (Ohbouchi et al., 1989; Ren et al., 2009). The approach builds on social balance processes to rebuild trust and incorporates them (Dirks et al., 2009). The strategies include apologies, penalties, punitive, compensation, price payments, redistribution of power and resettlement of account settlement expectations, rebalancing scales, and restoring expectations for damaged relationships theoretically (Shapiro, 1987; Dirks et al., 2009; Lewicki et al., 2012). 
The majority of investigating on the relational method has been experimental and interpersonal. This article argues that integrating partnership repair strategies like apologies and remuneration is potentially more successful than depending on a single violation of the trust. Much investigationalstudy has shown that reasons and restitution practice will influence reparations through the signals of remorse the scale of the payout, and the implicit motives behind repair methods are essential (Desmet et al., 2011). The results also indicate that the existence of this breach may influence the effectiveness of different trust repair techniques.At the organization's level, case studies indicate a fundamental component of restoring stakeholder confidence in an organization about repair tactics (Dietz et al., 2011; Gillespie et al., 2014; Eberl et al., 2015).

\subsection{Rule and control}

To facilitate the repair of trust following a breach, regulation, formal rules, and controls are theorized by limiting untrustworthy conduct and thus avoiding future regulations on organization-based violations of trust (Gillespie et al., 2009).This means organizations implementing structures that ensure credible positive contact and the avoidance of potential offensesand that rely on laws, rules of ethics, structures, punitive measures, policies, and incentives to restore trust.It has been seen that such control structures restore organizational trust, mainly if applied internally rather than actively. In sociological literature, the long history of the relationship between control and trust repair has a long history. Granovetter (1985) referred to institutional arrangements such as contracts, role, and authority structures as sub-social approaches. Based on these inadequately-socialized approaches, Shapiro (1987) claims that trust in vacuousness depends on norms, legislation and operational limitations organization structures and mechanisms and insurance policies such as agreements that offer alternate alternatives to personalized or embedded trust connections and in particular whether the trustees have no feasible tracking or regulating means.Shapiro (1987) argues in line with Zuker (1986), those impersonal trust regulators represent systemic structures that create trust and not practical assurance substitutes.

However, paradoxically, these sources of ambiguous trust offer opportunities and means to their abuse (Barber, 1983; Shapiro, 1987). The broader institutional framework of institutional norms and protections for development, preservation, and repair of trust is also illustrated by other sociological works focused on neo-institutional theorizing. The emphasis on social systems and norms is also apparent from Luhmann's (1979) definition of system trust, which encourages confidence relationships within organizations.

Sitkin et al. (1993) explain in their critical theoretical and empirical contributiontowhy theological solutions could have reduced productivity in compromised trust. Their analysis highlights two aspects of trust, firstly the trust that an employee can complete tasks consistently, and, second, a reduction that comes about if an employee's values are aligned with the societal values of the organization and challenge the general incongruity of value.They conclude that formal controls are only satisfactory to restore failure to reliability, not inconsistency.

\subsection{Cultural controls}

Another way to limit untrustworthy behavior and promote reliable conduct in organizations is organizational cultures and informal controls (McKendall et al., 1987). There is frequently trust treason in a corrupt, unethical, or lax organizational culture. The tactics of repair include the implementation of cultural changes that define and criticize principles, norms, and convictions that have provided for breaches of trust, human resources, processes that are symbolic messages, and guiding leadership that strengthens desired values and behaviors, and that promote and counter-cultural ethics.

This is an essential method for repairing trust despite research that indicates that immoral corporate environments will flourish both in the sense of workplace and social norms, even in violation of these expectations utilizing identity sharing (Ashforth et al., 1989). Sztompka (1999) describes the ethical collapse as a significant contributor to the question of the organization's morale, as trust in the way practitioners fulfill their position is the source of assumed modes of belief (Kramer, 1999).

Gillespie et al. (2014) recently suggested that changes to the corporate culture to reestablish the institutional and operational mechanisms of stakeholder trust in breach of corporate honesty alone would not be adequate.It correlates with Michael (2006) arguments, who laments that the prevailing approach to corporate crises is to solve the issue by way of legislative structures, and points out that regulations cannot override ethics and decision-making. Two other cultural recommendations, Gillespie et al. (2014), also recommend that in the sense of an infringement of honesty, remove the senior managers engaged in a loss in guards confidence and establish a positive image to workers who respect and hold on to what is right, would intensify and improve the organization. They describe the institutional changes and the role of the organization during the study of trust repair. 


\subsection{Accountability}

The idea is based on the view to restore trust by sharing transparently related knowledge about and collaborating with members on the corporate decision-taking cycle (Bachmann et al., 2015). The focus is on organizational reporting and monitoring. The responsibilities, transparency, and disclosure mechanisms provide a foundation for trust and the literature on corporative governance and public administration.

This mechanism is widely used in corporate governance and public management literature that suggests that trust is built on principles of accountability, transparency, and disclosure (Child et al., 2004). This partnership was built for businesses with a negative reputation at the beginning, and for corporations with the right image, the form of disclosure self vs. a third individual did not impact customer interest.

While highlighting the importance of transparent government for public trust, empirical evidence of the relationship between transparency and trust between the government is incorrect and knowledgeable.Grimmelikhuijsen et al. (2013), for example, reported that the effect of accountability on government trust was low and often harmful.Grimmelikhuijsen et al. (2014) further found that only a minority of people with no direct awareness of the policy issue and weak predisposition to the government have a positive relationship between openness and citizen sense of confidence in the system. Such experimental results indicate that the connection between transparency and trust is far from clear or straightforward in structural and organizational environments and requires further empiric evaluation, and how such effects turn into a single trust solution setting.

\subsection{The transition of trust}

This mechanism concentrates on the position of third parties in rebuilding trust, because trust may be transferred by the delivery of certificates and participation, affiliations, and endorsements from a reputable group to a tainted group. Third-party partnerships have been developed that allow new parties to satisfy their existing relationship eligibility criteria when information or experience is scarce (Shapiro et al., 1987). This is achieved by moving aspirations and incentives into new partnerships. In informal situations, the effect of third party assistance has also equal to the direct perception of the other party (Ferrin et al., 2006). McEvily et al. (2003) also defined transfers as a crucial process through which trust works as an operational mechanism that generates convergence and eliminates the grid.

An example of organizational trust transfer is a case study by Mueller et al. (2015). In this analysis, Mueller et al. (2015) described the transition of trust from an independent parliamentary committee overseeing the investigation to the affected audit firms as one main component of the restoration trust. Restricted research has individually analyzed the potentially important function of the trust transition in the restoration of the corporate reputation relative to other trust recovery methods. However, the institutional literature contains sound-related literature on the effect of spillover legitimacy (Haack et al., 2014).

\subsection{The trust repair models}

The phased models of trust recovery describing the measures and policies that a transgressor organization is to take in the rebuilding of trust are worthy of note in research on organizational trust repair.Usually, such models include some of the above-enumerated structures for trust repairs. These models comprise Lewicki et al. (1996), Pfarrer et al. (2008), and Gillespie et at. research (2009).

Lewicki et al. ( 1996) suggested the first phase model: (1) identifying and acknowledging that a violation has taken place, (2) assessing the extent of the violation defining what or who triggered the violation; (3) understanding the detrimental impact of the incident on trust and (4) taking liability for it. This model, therefore, combines the sensemaking and partnership processes for the repair of trust.

Gillespie et al. (2009) suggested a trust recovery model following a failure at an organizational level. Their study focused on trust, crisis management, structural transformation, and structures and multilevel theory to indicate that the understanding of the trustworthiness of an organization is shaped by indications four internal management and management, culture and environment organizational components; framework and processes; and external policy and two external management and governance components. They recommended a four-stage trust repair model, which incorporates much of the examined trust repair mechanisms.

The following four stages and the underlying repair mechanisms are described: (1) Immediate reactions, such as verbal approval, a note of an ongoing inquiry, and early action about the identified triggers during the first three days of the crisis. (2) Diagnosis of the causes of the failure in a timely, reliable, and straightforward treatment of the causes of failure. 
Mechanisms of sense-making and clarity. (3) Reform in procedures to prevent potential transgressions and show increased trust in the organization. This involves, where necessary, introducing systemic diagnosis-based financial, administrative, economic, political, and leadership changes, along with apologies, reparations, and punishments. The processes of organization, society, and connections. (4) evaluate the effectiveness of repair initiatives and track and advise the importance of ongoing improvements and reforms. Those are the internal, cultural, and sensory processes.

Pfarrer et al. (2008) particularly conceptualize post-crisis reintegration. The author described a reintegration mechanism for stakeholders after an organizational transgression. The author describes reintegration as the method of reconstituting the credibility of stakeholder ties, destroyed by the corruption of organizations, focused on the literature on stakeholder philosophy, organization's justice,image management, and crisis management. Thus the author recommends these steps that should answer evolving issues and interests of stakeholders in the reintegration process: (1) What happened? The discovery requires an open declaration, independent investigation, and collaboration (2) How did this occur? An indication of acceptance of misconduct, remorse, guilt, and apology; (3) When is the organization supposed to be punished? Penance like approval of judgment, recognition without opposition to punishment; and (4) What changes were made? Rehabilitation, with internal or exterior adjustments. The underlying concept behind the model is that rehabilitation is more feasible if the party meets the expectations of key stakeholders and competes at each point of rehabilitation, which is a widespread view among shareholders on the breach and appositeness of the operations of the organizations (Pfarrer et al., 2008).

There are similarities between these two system areas: both rely on the strongly related principles of integrity and organizational trustworthiness, are intentionally normative and describe a phased cycle of supplementary behavior, meaning that trust may be returned to organizations by having sufficient internal organizational changes with external governance (Gillespie et al., 2014). These models demonstrate various facets of the mechanism and create innovative proposals.

The exciting aspect of these three models is that they clearly emphasize prompt and effective logical practice. When a violation happens, the leaders of the organization must assess the extent of the violation, recognize the source, apologize, provide remedies, initiate analysis, and implement internal and external improvements. Some of the main principles is also a trust in a regulatory authority to resolve the lack of trust. In other terms, administrators may control the understanding among clients of the trustworthiness of the organization and the validity of its behavior after abuse. Therefore, managers are usually required to repair trust in the face of weakened trust.

There are two academic papers released by the Institute of Business Ethics (Dietz et al., 2011; 2012), which are used to explain, endorse and extend the phase-styles of trust repairing and the recommendations guiding them with case studies of organizations. Such studies clearly outlined a critical dilemma that frequently becomes evident throughout the reparation of the organizational trust - the option between a legalist and a relation-based strategy. The regulatory direction aims at mitigating the financial burden of the business and avoids disclosure to media by explaining loss, for instance, by reticence, rejection, lack of accountability, superimposition, or restraint on claims. Poppo et al.(2010) suggest that this approach is best applied when organizations are scandalized. Nevertheless, the partnership strategy is focused on the alternate principle that the only way to protect the integrity of the company is by effective management of interactions between the entity and its stakeholders, for instance, by accountability, direct contact, respect for the effect of the default on parties concerned and resolution. Throughout the majority of situations, these two methods are inconsistent and produce long-term outcomes somewhat different.

\subsection{The metaphysics of trust repair}

The fundamental trust repair literature is based on the functionalist presumption that trust can be a set of relatively straightforwardrequirements(Möllering, 2006). For such studies, the jargon of the principle of heterogeneity that involves knowledge of precedents and effects of trust repair and explanations for the causal relations between dependent and independent variables. The emphasis of these scholarships is on evaluating trust repair behavior and explaining individual trust repair response variables, which form recovery. Apology and denial are frequently used independent variables reticence excuse, financial compensation, penance, and justification (Tomlinson et al., 2004).

\section{Discussion and future study on organizational trust repair}

The standard trust repair experiments are focused on a mechanical model as trust breaks; the trust must be restored. While these studies are profoundly insightful and realistic, they do not represent the dynamic nature of the reparation of organizational trust. Many trust studies challenge the fundamental premises of most scholars that trust can be established in many partnerships within an organization and that administrators should form the bond of trust with both. 
Those two main concepts are the spectrum of shared interests and executives that often concern revolutionary thinkers, overlooking opposing intent in the administration of labor relations. Child et al. (2004) concluded that employees had so much trust in organizations which have struggled gradually. The argument that strong institutional forces support the impact of employee engagement and trust has been rejected by Thompson et al. (2011) and by BijlsmaFrankema et al. (2015) that trust can be remedied once distrust is created is questioned.

The study of the literature shows there is no interpretive work on the repair of organizational trust. In comparison, there is little that focused on interpretive reasoning rather than genuinely interpretive thought. Intra-organizational trust study (Siebert et al., 2015), there are progressive views under-represented, which is also apparent in corporate trust repair studies. Child et al. (2004) research alluded to earlier indicated that a rise in aggressive takeover losses caused breaches of trust in many contemporary organizations and hierarchical systems in workplaces, which encouraged differentiation and separation through large pay differentials and unequal compensation for success. The analyst also claimed that economic ideology fostered the equal redistribution of capital and supported the less desirable care of individuals under competitive employability. Given the growing recognition of employee trust in organizational efficiency, which is apparent in functionalist literature, employee anxiety, organizational dissatisfaction, and disengagement seemed to grow.

Alan Fox's research on this is essential and powerful. This is important with Fox (1969) to make two significant improvements to the sociological trust accounts of organizations. The first is a macro-sociological account of the references in industrial relations in the 1960s and 1970s in unitarist, pluralist, and radical ways. The second is a microsociological account of how social relationships shape trust dynamics in the workplace, especially power relations and the division of labor into bureaucratic organizations. Fox's philosophy of trust also helps to clarify the connection between the organization at operation, the arrangement, and the ties at control between workers and management. Research by Fox (1974) refers to an institutionalized loss of employees' interest by distrust, envy, misinterpretation of people's motivations, and lack of cooperation. These strategies are evolving in contemporary studies of organizational trust restoration (Mueller et al., 2015), but more research must investigate these challenges further.

Siebert et al. (2015) suggest that one drawback of trust and trust repair research is that, while avoiding external factors, it is still restricted to what occurs within organizations. The author struggles to tackle issues such as recessions, global job patterns, social disorder, the loss in trust in governments, policy, and philosophy by relying on the organization as a unit of study. Some critical structural variables such as control influences, governance systems, and the effects of the more extensive political system need to be considered when evaluating whether organizations will maintain corporate trust between employees. More important trust repair viewpoints will allow researchers to criticize or problem-size the underlying premises, to pose more insightful questions that breach current model limitations and to produce new theoretical and functional insights.

These essential viewpoints to recover trust are not the only path forward;thearticlefindings sums up other theoretical solutions to discussions on the rehabilitation mechanism, method theory, and structural theory. The reviewers point to more information on trust repair studies in recent studies by Bachmann et al. (2015), Dirks et al. (2009), and Kramer et al. (2010).

\subsection{Debate on institutional agencies and trust repair}

Most of the studies of trust repair place excessive belief in the quality of the management team to maintain trust and neglect external factors that can influence the reintegration of organizations. (Möllering, 2006). A change from an organization's focus on institutional and social trust could shed light on why, despite their genuine efforts, some organizations cannot repair trust (Child et al., 2004).

The system and organization will also expand intellectual knowledge into the repair of trust and have functional consequences for organizations. A rebalancing recognizes debate between the system and organization (Giddens, 1984), takes account of unforeseen consequences of managerial behavior that allow trust researchers to identify shortcomings of present rules and avoid increasing excessive reparation standards.In their analysis of trust reparation strategies for functions such as finance a global financial crisis, for example, Gillespie et al. (2012) apply this double perspective to trust reparations efforts within the banks alone. This may not result if the author fails to recognize that the structure of its governance requires further profound or revolutionary reform.

\subsection{Organizational outlook}


Regarding the theoretical and historical existence of much of the trust repair literature, the emphasis may appear relevant in offering a more complex reason for how trust is preserved in businesses and influenced by higher rates of organizations. The early institutionalists institutions maintained that organizations guaranteed systemic hierarchies through their embedding in a more extensive hierarchical system and eventually pursued a specific plan of action.

Unlike the early institutionalism that predicts that organizations have a degree they do not have since they are actively incorporated in neo-institutional fields, determinism has been questioned in recent institutional theory, boost agency position across organizational stakeholders (Lawrence et al., 2006). Institutional work defined as intelligent, institutional action is such an aspect of institutional theorization (Lawrence et al., 2006). Institutional research offers a complex viewpoint on the interaction between actors and institutions and describes three institutional structures that establish, sustain, and distort institutions (Dacin et al., 2010; Lok et al., 2013).

Throughout recent years, researchers have examined another dimension of institutional research in the face of functional instability. The main focus of this research is on institutions at vulnerable times and where new entrants, violations of breakdowns, or external challenges challenge the organization and, support work can be noticed (Lok et al., 2013). There are striking similarities between researches of breaks of trust and practice disorders and institutional literature that can shed light on new ways to theorize reparation of trust.The systemic solution to repairing trust will, therefore, open the entrances for evaluating more broad structures, such as the judicial structure, sects, and political processes of organizations trust repair.

\subsection{The trust repair process theory}

While literature agrees that trust is a process itself, its processual essence is still understudied (Möllering, 2006; Khodyakov, 2007). Recent proposals have been made for a method analysis methodology to create more nuanced trust repairs accounts and related issues (Nooteboom, 1996; Bachmann et al., 2015). These methods, which integrate process instead of theorizing variants, have several points to applaud as they specifically interact with the empirical essence of trust repair. Recently a dynamic model of the process of distrust that explains how and why distrust is firmly enshrined in self-improvement (Bjilsma-Frankema et al., 2015).Since weaknesses of organizational trust not only reduce confidence but also cause active disbelief, this study has provided useful lessons to recover trust. It stresses the essential need to resolve expectations in inconsistency in meaning to address and rebuild mistrust.

Many trust repair studies are being defined by attributing to the abilities of management to rebuild confidence via a comparatively uncontroverted organization clear recommendations, such as the mentioned conceptual and material trust repair approaches and activities. Siebert et al. (2014) challenged the inflated managerial agency and suggested that it could, sometimes, be adequate to leave things alone. This counterintuitive inaction strategy represents a threat to the identity of managers and does not correspond to the dominant link between adaptation and development. However, this method may indicate that, sometimes, abandoning the trust cycle, for example, with the influence of time-dependent deteriorating memory or distracting corporate stakeholder interest will function well; yet, empirical research is required.

\section{Conclusion}

The author provided a systematic overview of the current philosophical and academic research on repairing trust in organizations and institutions. The author thus identified the prevailing ontological and epistemological frameworks taken up in literature, which take a functionalistic normative viewpoint based on the language of variance. While these prevailing frameworks have established the required and helpful foundations for this evolving area, the author argues this research needs to be complemented with crucial and revolutionary viewpoints, to deepen comprehension of the constraints and macro-incidences on the repair of organizational trust. Thus, this article urges prospective researchers to incorporate systemic agency and organizational viewpoints and to concentrate on the sophisticated and processual essence of organizational trust repair.

\section{References}

Ashforth, B. E., \&Mael, F. (1989). Social identity theory and the organization. Academy of management review, 14(1), 20-39.

Bachmann, R., \&Inkpen, A. C. (2011). Understanding institutional-based trust-building processes in interorganizational relationships. Organization Studies, 32(2), 281-301.

Bachmann, R., Gillespie, N., \&Priem, R. (2015). Repairing trust in organizations and institutions: Toward a conceptual framework. Organization Studies, 36(9), 1123-1142.

Barber, B. (1983). The Logic and Limits of Trust, Rutgers University Press. New Brunswick NJ. 
Barr, N. (2020). Economics of the welfare state. Oxford University Press, USA.

Burnham, P., Lutz, K. G., Grant, W., \& Layton-Henry, Z. (2008). Research methods in politics. Macmillan International Higher Education.

Child, J., \& Rodrigues, S. B. (2004). Repairing the breach of trust in corporate governance. Corporate Governance: An International Review, 12(2), 143-152.

Dacin, M. T., Munir, K., \& Tracey, P. (2010). Formal dining at Cambridge colleges: Linking ritual performance and institutional maintenance. Academy of Management Journal, 53(6), 1393-1418.

Desmet, P. T., De Cremer, D., \& van Dijk, E. (2011). In money we trust? The use of financial compensations to repair trust in the aftermath of distributive harm. Organizational Behavior and Human Decision Processes, 114(2), $75-86$.

Dietz, G., \& Gillespie, N. (2011). Building and restoring organizational trust. London: Institute of Business Ethics.

Dietz, G., \& Gillespie, N. (2012). Recovery of trust: Case studies of organizational failures and trust repair (Vol. 5). London: Institute of Business Ethics.

Dirks, K. T., Lewicki, R. J., \& Zaheer, A. (2009). Repairing relationships within and between organizations: building a conceptual foundation. Academy of Management Review, 34(1), 68-84.

Eberl, P., Geiger, D., \&Aßländer, M. S. (2015). Repairing trust in an organization after integrity violations: The ambivalence of organizational rule adjustments. Organization Studies, 36(9), 1205-1235.

Elsbach, K. D. (1994). Managing organizational legitimacy in the California cattle industry: The construction and effectiveness of verbal accounts. Administrative science quarterly, 57-88.

Ferrin, D. L., Dirks, K. T., \& Shah, P. P. (2006). Direct and indirect effects of third-party relationships on interpersonal trust. Journal of applied psychology, 91(4), 870.

Fox, A. (1966). Industrial sociology and industrial relations: An assessment of the contribution which industrial sociology can make towards understanding and resolving some of the problems now being considered by the Royal Commission (No. 3). HM Stationery Office.

Fox, A. (1974). Beyond contract: Work, power, and trust relations. Faber \& Faber.

Fulmer, C. A., \& Gelfand, M. J. (2012). At what level (and in whom) we trust: Trust across multiple organizational levels. Journal of management, 38(4), 1167-1230.

Gillespie, N., \& Dietz, G. (2009). Trust repair after an organization-level failure. Academy of management review, 34(1), 127-145.

Gillespie, N., Hurley, R., Dietz, G., \& Bachmann, R. (2012). Restoring institutional trust after the global financial crisis: A systemic approach.

Gillespie, N., Dietz, G., \&Lockey, S. (2014). Organizational reintegration and trust repair after an integrity violation: A case study. Business Ethics Quarterly.

Granovetter, M. (1985). 1985: Economic action and social structure: the problem of embeddedness, American Journal of Sociology 91, 481-510.

Grimmelikhuijsen, S., Porumbescu, G., Hong, B., \&Im, T. (2013). The effect of transparency on trust in government: A cross- national comparative experiment. Public administration review, 73(4), 575-586.

Grimmelikhuijsen, S. G., \& Meijer, A. J. (2014). Effects of transparency on the perceived trustworthiness of a government organization: Evidence from an online experiment. Journal of Public Administration Research and Theory, 24(1), 137-157.

Haack, P., Pfarrer, M. D., \& Scherer, A. G. (2014). Legitimacy- as- feeling: How to affect leads to vertical legitimacy spillovers in transnational governance. Journal of Management Studies, 51(4), 634-666.

Hope-Hailey, V., Dietz, G., \& Searle, R. (2012). Where has all the trust gone?.

Kim, P. H., Dirks, K. T., \& Cooper, C. D. (2009). The repair of trust: A dynamic bilateral perspective and multilevel conceptualization. Academy of Management Review, 34(3), 401-422.

Khodyakov, D. (2007). Trust as a process: A three-dimensional approach. Sociology, 41(1), 115-132.

Kramer, R. M. (1999). Trust and distrust in organizations: Emerging perspectives, enduring questions. Annual review of psychology, 50(1), 569-598.

Kramer, R. M., \& Lewicki, R. J. (2010). Repairing and enhancing trust: Approaches to reducing organizational trust deficits. Academy of Management annals, 4(1), 245-277.

Lamin, A., \& Zaheer, S. (2012). Wall Street vs. Main Street: Firm strategies for defending legitimacy and their impact on different stakeholders. Organization Science, 23(1), 47-66.

Lawrence, T. B., \& Suddaby, R. (2006). 1.6 institutions and institutional work. The Sage handbook of organization studies, 215-254.

Lewicki, R. J., \& Bunker, B. B. (1996). Developing and maintaining trust in work relationships. Trust in organizations: Frontiers of theory and research, 114, 139. 
Lok, J., \& De Rond, M. (2013). On the plasticity of institutions: Containing and restoring practice breakdowns at the Cambridge University Boat Club. Academy of Management Journal, 56(1), 185-207.Luhmann, N. (1979). 1979 Trust and power. Chichester: Wiley.

McEvily, B., Perrone, V., \& Zaheer, A. (2003). Trust as an organizing principle. Organization science, 14(1), 91-103.

Michael, M. L. (2006). Business ethics: The law of rules. Business Ethics Quarterly, 475-504.

Möllering, G. (2001). The nature of trust: From Georg Simmel to a theory of expectation, interpretation and suspension. Sociology, 35(2), 403-420.

Mueller, F., Carter, C., \& Whittle, A. (2015). Can audit (still) be trusted?. Organization Studies, 36(9), 1171-1203.

Nooteboom, B. (1996). Trust, opportunism and governance: A process and control model. Organization studies, 17(6), 985-1010.

Pfarrer, M. D., Decelles, K. A., Smith, K. G., \& Taylor, M. S. (2008). After the fall: Reintegrating the corrupt organization. Academy of Management Review, 33(3), 730-749.

Poppo, L., \&Schepker, D. J. (2010). Repairing public trust in organizations. Corporate Reputation Review, 13(2), 124141.

Shapiro, S. P. (1987). The social control of impersonal trust. American journal of Sociology, 93(3), 623-658.

Siebert, S., Martin, G., Bozic, B., \& Docherty, I. (2015). Looking 'beyond the factory gates': Towards more pluralist and radical approaches to intraorganizational trust research. Organization Studies, 36(8), 1033-1062.

Siebert, S., \& Martin, G. (2014). People management rationales and organizational effectiveness. Journal of Organizational Effectiveness: People and Performance.

Sitkin, S. B., \& Roth, N. L. (1993). Explaining the limited effectiveness of legalistic "remedies" for trust/distrust. Organization science, 4(3), 367-392.

Sztompka, P. (1999). Trust: A sociological theory. Cambridge University Press.

Thompson, P. (2011). The trouble with HRM. Human Resource Management Journal, 21(4), 355-367.

Tomlinson, E. C., Dineen, B. R., \& Lewicki, R. J. (2004). The road to reconciliation: Antecedents of victim willingness to reconcile following a broken promise. Journal of management, 30(2), 165-187.

Tomlinson, E. C., \&Mryer, R. C. (2009). The role of causal attribution dimensions in trust repair. Academy of Management Review, 34(1), 85-104. 